\title{
Article
}

\section{Beverage-Agarose Gel Electrophoresis: An Inquiry-based Laboratory Exercise with Virtual Adaptation ${ }^{1}$}

\author{
Steven C. Cunningham, ${ }^{*}$ Brad McNear, ${ }^{\dagger}$ Rebecca S. Pearlman, ${ }^{\ddagger}$ and Scott E. Kern ${ }^{*}$
}

*Department of Oncology, The Sidney Kimmel Cancer Research Center at Johns Hopkins University School of Medicine, Baltimore, MD 21231; ${ }^{\dagger}$ Northglenn High School, Northglenn, CO 80260-6003; and ‡Department of Biology, Krieger School of Arts and Sciences, Johns Hopkins University, Baltimore, MD 21218

Submitted January 5, 2006; Accepted April 10, 2006

Monitoring Editor: Elizabeth Vallen

\begin{abstract}
A wide range of literature and experience has shown that teaching methods that promote active learning, such as inquiry-based approaches, are more effective than those that rely on passive learning. Gel electrophoresis, one of the most common laboratory techniques in molecular biology, has a wide range of applications in the life sciences. As such, we chose it as a platform to expose high school and undergraduate students to the active process of scientific inquiry in general, while specifically teaching electrophoresis. First, we optimized DNA electrophoresis in the laboratory by using common beverages instead of standard media (e.g., Tris-based media). Second, we adapted this laboratory process of progressive optimization to a Web-based format in which students had to achieve all the same steps of optimization by performing serial electrophoreses. And third, we evaluated the use of this entirely Web-based virtual laboratory exercise in high school and undergraduate biology courses. Students learned fundamental and practical principles of electrophoresis, while experiencing the essential inquiry-based process of optimizing a technique, and they also enjoyed it. Our findings provide a readily accessible, inexpensive, and intriguing technique for teaching electrophoresis and the progressive optimization of a laboratory technique.
\end{abstract}

\section{INTRODUCTION}

Inquiry-based teaching is supported by the cognitive science literature (Bransford et al., 2000), by practical examples of its success (Rehorek, 2004), and by expert consensus (Chiappetta, 1997; Kenny, 1998; Leonard, 2000; Committee on Undergraduate Biology Education to Prepare Research Scientists for the 21st Century, 2003; Howard and Miskowski, 2005). The Center for Inquiry-Based Learning defines inquiry-based teaching as "the art of creating situations in which students take the role of scientists." Inquiry, in this sense, is defined as "asking questions ... provid[ing] students with concrete, active learning experiences;" in short, it is "what scientists do" (Budnitz, 2001).

DOI: $10.1187 /$ cbe.06-01-0139

Address correspondence to: Scott E. Kern (sk@jhmi.edu).

\footnotetext{
${ }^{1}$ This research article assesses the effectiveness of a novel exercise, termed The BAGE Page. To the extent that it presents a conflict of interest, we disclose that we produced the exercise.
}

Inquiry requires interest and, as such, methods of increasing the level of student interest and cognitive involvement in the pedagogical process are valuable. The use of common household reagents for scientific experimentation is inherently alluring because technical problems and opportunities interact in unexpected ways: As novel problems present themselves to the experimenter, they provide opportunities that require active thinking to overcome. Examples of common household substances in technical demonstrations, such as the crude extract of red cabbage as an indicator of $\mathrm{pH}$, egg yolk as a powerful emulsifier, and crystalline semiconductor minerals as electrical diodes for crystal radios, are typically memorable for students.

Although impure, common household reagents such as beverages are of consistent constitution and quality due to commercial and governmental quality-assurance standards. Furthermore, brewed beverages such as draft root beer and beer are excellent substrates for experimental application to DNA electrophoresis due to the known complexity of anions, the most prevalent being phosphate, chloride, lactate, sulfate, and pryroglutamate (Klampf, 1999). 
Potentially adverse qualities of brewed beverages as media for DNA electrophoresis include dissolved $\mathrm{CO}_{2}$ that may cause bubbles in the gel, excess acidity that may degrade DNA, the presence of colored flavanoids that may obscure detectable signals from DNA within the gel, the activity of enzymes such as DNases produced by yeast that may degrade the DNA, and the presence of proteins and carbohydrates that may precipitate when heated.

Electrophoresis is arguably the most commonly used technique in molecular biology, making it an important component of any high school or undergraduate biology curriculum. To incorporate inquiry into the teaching of electrophoresis in a manner likely to raise and maintain the interest of the students, we developed a common household-reagent modification of electrophoresis. First, we optimized DNA electrophoresis in the laboratory using common beverages instead of standard media. Second, and most importantly from a practical perspective, this actual laboratory process of progressive optimization, including each of the laborious and time-consuming steps, was condensed and adapted to the more efficient Web-based format for use inside or outside of the laboratory. And third, the Webbased exercise was evaluated in high school and undergraduate biology courses. In this way, we expose students to the practical process of scientific inquiry in general, while specifically teaching electrophoresis. Student impressions were assessed with a questionnaire, whereas pre- and postexercise quizzes evaluated the pedagogical value of the exercise.

\section{OBJECTIVES}

The objectives of this exercise are as follows:

- To introduce DNA gel electrophoresis in a fun, inquirybased manner to high school and undergraduate students.

- To encourage students to think critically, beyond the given protocol.

- To show students how an experiment may be optimized from an uncertain starting point.

- To convey practically the necessary knowledge base required to perform and discuss DNA electrophoresis.

- To provide a Web-based forum through which students may perform virtual experiments allowing them to achieve all of the above-mentioned objectives in a timely and effective manner.

\section{METHODS}

\section{Laboratory Experiments}

A naturally brewed draft root beer (Natural Brew Draft Root Beer, Smucker Quality Beverages, Chico, CA), an artificially flavored root beer (Root Beer, Giant Brands, Landover, MD), and a mainstream American beer (Budweiser, Anheuser-Busch, St. Louis, MO) were chosen for these experiments. Media were made by adjusting the $\mathrm{pH}$ to approximately 7.5 with $\mathrm{NaOH}$ or $\mathrm{LiOH}$. Beverages were diluted with deionized water to working solutions of 0.1 and $0.05 \times$ in 1 l. If cloudy, diluted beverages were passed through a $0.2-\mu \mathrm{m}$ filter (e.g., PN12675; Pall Corporation, Ann Arbor, MI) just before use.

All gels were 1.0\% agarose (e.g., type I low EEO; Sigma-Aldrich, St. Louis, MO). For a 100-ml gel, $1 \mathrm{~g}$ of agarose was dissolved either in $100 \mathrm{ml}$ of $0.1 \times$ media by heating to boiling for $\sim 2$ min or until no agarose particles were visible. Alternatively, to avoid boiling beverage media, agarose was first dissolved in $50 \mathrm{ml}$ of deionized water, and, after cooling to $\sim 55^{\circ} \mathrm{C}$, added to an equal volume (50 $\mathrm{ml}$ ) of warm $0.1 \times$ working solution, and a DNA dye was incorporated. For these experiments, ethidium bromide (e.g., Fisher Scientific, Fair Lawn, NJ) for a final concentration of $300 \mathrm{ng} / \mathrm{ml}$ (e.g., 30 $\mu \mathrm{l}$ of $10 \mathrm{mg} / \mathrm{ml}$ stock solution) was used, but many other less toxic dyes are commercially available. The same concentration of dye was added to the remaining $950 \mathrm{ml}$ of $0.05 \times$ solution, which served as the electrophoresis medium. The gel solution was poured into a mold containing a comb and allowed to cool and solidify. To avoid electrolyte exhaustion (or to treat when it occurred), recirculation of the beverage medium from the cathode to the anode was performed with a pump and tubing. As little as 1-2 drops/s was sufficient.

A standard DNA ladder (e.g., 1-100 ng of 1-kb DNA Ladder; Invitrogen, Carlsbad, CA) was loaded onto the gels in various concentrations. Electrophoresis was performed for approximately $1 \mathrm{~h}$ at $125 \mathrm{~V}$ using a horizontal rig (e.g., MGU-599; CBS, Del Mar, CA). Using chilled medium $\left(4^{\circ} \mathrm{C}\right)$ increased the quality of the bands slightly, but was not necessary. DNA was visualized using UV light (e.g., Eagle Eye II still video system; Stratagene, La Jolla, CA). Postelectrophoresis ethidium bromide incubations, when necessary to increase signal-to-noise ratio, were performed in deionized water at $4^{\circ} \mathrm{C}$ for several hours or overnight.

\section{Web-based Adaptation}

To achieve a more efficient and practical use of the experimental procedure in the classroom, we adapted the actual optimization to a virtual, interactive platform termed "The BAGE Page" (Figure 1 is the home page; the entire interactive site is available at https:// jshare.johnshopkins.edu/scunnin9/BAGE_Page/index.htm). This Web-based exercise was designed using FrontPage (Microsoft, Redmond, WA).

\section{Classroom Evaluation}

Students were asked to complete a survey (Table 1) to assess their impressions of the exercise and to take a pre- and postexercise quiz (Table 2; see Supplemental Material) to evaluate pedagogical value. All three forms were submitted electronically and anonymously for analysis to one of us (S.C.C.) who was not involved with teaching the students or administering the exercise. Multiple answers for any single question were not included in the analysis.

\section{Statistics}

Chi-square and Fisher's exact tests were used to compare categorical variables, such as the survey results, and a single-tailed paired student's $t$ test was used to compare the pre- and postexercise quiz scores.

\section{RESULTS}

\section{Laboratory Optimization of Beverage-Agarose Gel Electrophoresis (BAGE)}

Initial attempts to perform DNA electrophoresis in beverages were unsuccessful, resulting in no visible bands (Figure $2 \mathrm{~A}$ ), even when $\mathrm{pH}$ was adjusted to $\sim 7.5$. However, a postelectrophoresis incubation of the gel at $4^{\circ} \mathrm{C}$, to allow ethidium ions to migrate to the DNA, produced faint bands (Figure 2B). Given that common household reagents such as brewed beverages (e.g., root beer and beer) may be expected to contain yeast-derived DNases that require divalent metal ions for activity, we sought to ascertain whether the chelator EDTA was necessary for protecting the DNA; we performed electrophoresis with and without EDTA and found it not to 


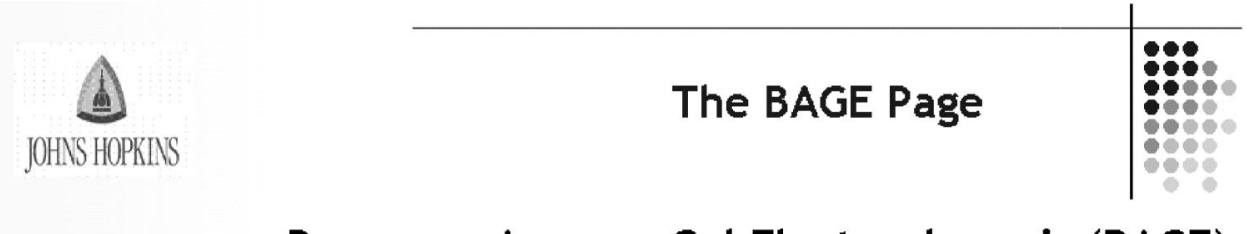

\section{Beverage-Agarose Gel Electrophoresis (BAGE)}

Home Knomledge Base

Pre-BAGE Quiz Begin Optimization

Background

References

Protocol

Post-BMGE Quiz/Feedback

WELCOME to the BAGE Page. The purpose of this web is to provide an engaging approach to learning about problem-solving and DNA electrophoresis at the same time. This is accomplished by conducting virtual web-based experiments to optimize a common laboratory technique from an unusual starting point. DNA electrophoresis is generally done in salt solutions of Tris or borates, but we are going to optimize the technique using common beverages instead.

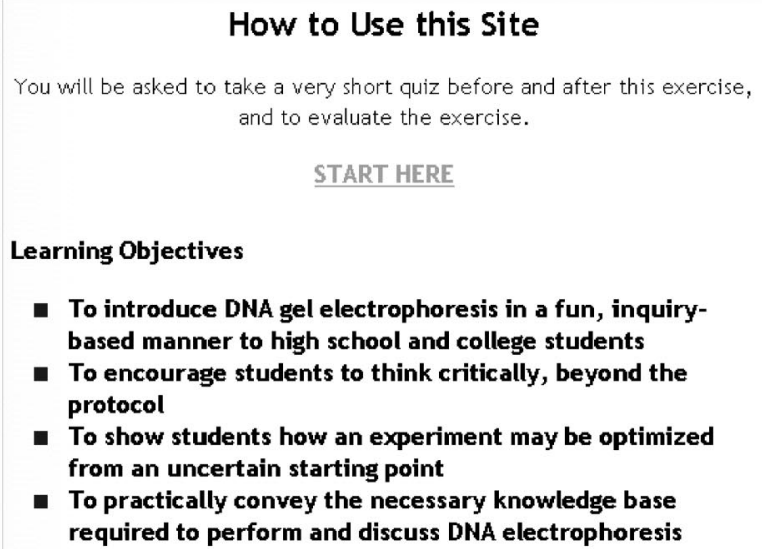

Figure 1. Home page of the Web site for The BAGE Page (the entire Web site is available at https://jshare.johnshopkins.edu/scunnin9/ BAGE_Page/index.htm).

be required (Figure 2C). Because of high autofluorescent, potentially flavanoid-related background from a naturally concentrated $(0.67 \times$ after adjusting $\mathrm{pH})$ beverage media, we sequentially thirded the concentration of the beverage to $0.22 \times$ (our unpublished data) and to $0.07 \times$, and despite an improved signal-to-noise ratio, the gel developed a moving

Table 1. High school versus undergraduate student impressions of The BAGE Page

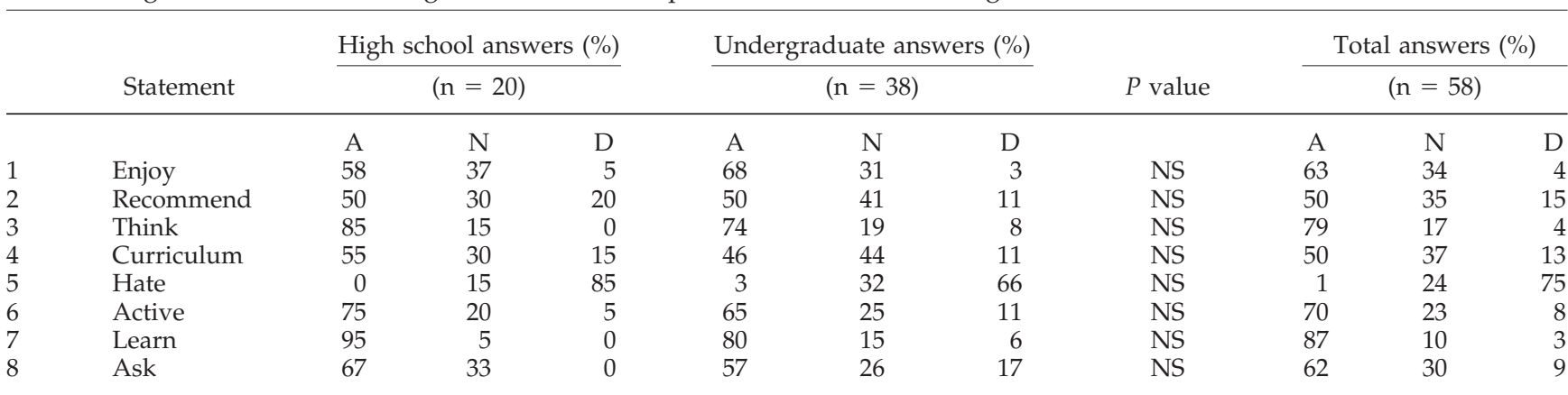

High school and undergraduate students were asked to rate their agreement with the following eight statements regarding The BAGE Page exercise: 1) It was enjoyable; 2) I would recommend it to a friend; 3) It made me think; 4) It should be adopted as a standard part of the curriculum; 5) I hated every minute of it; 6) It was an active process for me; 7) I learned something from it; and 8) It made me ask questions, for example, 'Why did I get that result?' Options included strongly agree, agree, neutral, disagree, and strongly disagree. A, all agrees; N, neutral; and D, all disagrees. 
Table 2. Pre- and postexercise undergraduate quiz scores

\begin{tabular}{|c|c|c|c|c|}
\hline \multirow[b]{2}{*}{ Question } & \multicolumn{2}{|c|}{$\%$ correct } & \multirow[b]{2}{*}{ Change } & \multirow[b]{2}{*}{$P$ value } \\
\hline & $\begin{array}{c}\text { Pre } \\
(\mathrm{n}=45)\end{array}$ & $\begin{array}{c}\text { Post } \\
(\mathrm{n}=38)\end{array}$ & & \\
\hline 1 & 95.6 & 92.1 & -3.5 & 0.293 \\
\hline 2 & 95.6 & 100 & 4.4 & 0.293 \\
\hline 3 & 93.2 & 97.3 & 4.1 & 0.293 \\
\hline 4 & 78.4 & 89.5 & 11.1 & 0.0095 \\
\hline 5 & 78.0 & 89.5 & 11.4 & 0.0095 \\
\hline 6 & 22.2 & 44.1 & 21.9 & 0.0095 \\
\hline 7 & 68.2 & 94.7 & 26.6 & 0.0095 \\
\hline Mean & 75.9 & 86.7 & 10.9 & 0.017 \\
\hline
\end{tabular}

* Questions 1-3 were designed to be relatively easy and 4-7 relatively difficult.

zone of deformity in the thickness of the gel at the anode end (Figure 2D). A review of the history of DNA electrophoresis and its literature reveals similar phenomena (Gordon et al., 1951; Brody and Kern, 2004), and they were attributed to electrolyte exhaustion. We addressed this possibility by a simple increase in the effective volume of the anodal reservoir by recirculation of the medium from cathode to anode reservoirs using a simple pump-and-tubing apparatus $(\sim 2$ drops/s), which prevented the deformity (Figure 2E). Filtering the medium decreased the autofluorescent background (our unpublished data). Boiling-induced precipitation in the medium was avoided by a delay in the addition of beverage until after the boiling dissolution of agarose, further improving the signal in comparison with background (Figure 2F). Together, dilution, recirculation, filtering, and avoidance of boiling provided sufficiently high-quality results that the postelectrophoretic ethidium bromide incubation was no longer necessary and low-molecular-weight bands $(<2000$ base pairs) were resolved in 30-60 $\mathrm{min}$. Extending electro-

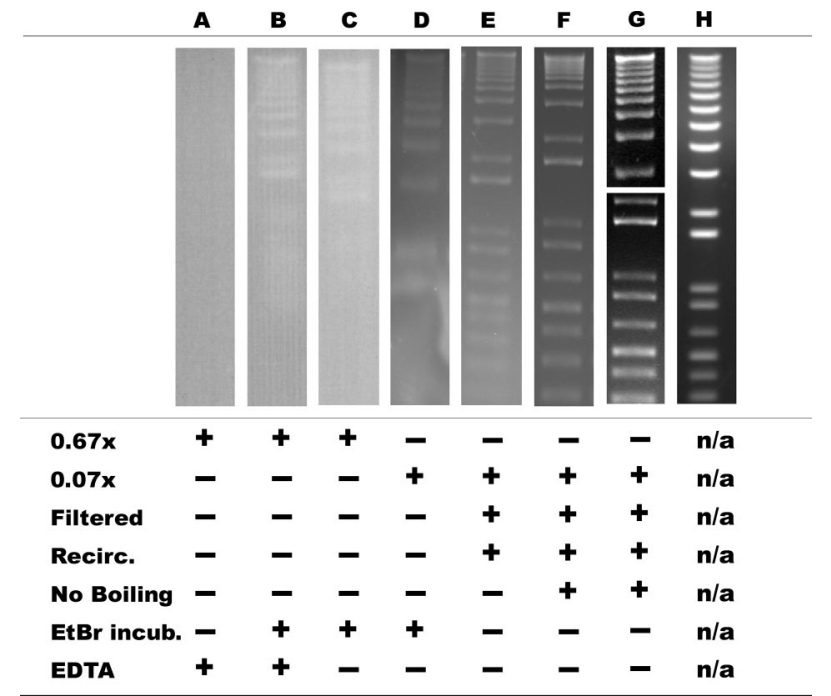

Figure 2. Progressive optimization of DNA electrophoresis in beverage-based media. See text for details. phoresis for longer periods ( $2 \mathrm{~h}$ total) allowed the clear separation of the high-molecular-weight bands (up to $\sim 12,000$ base pairs) (Figure 2G), providing an image of comparable quality to a standard electrophoretic method (Figure 2H), as first performed in 1972 (Aaij and Borst, 1972; Hayward and Smith, 1972).

\section{Web-based Adaptation}

Having successfully optimized DNA electrophoresis using common beverages instead of standard media, we adapted the actual optimization to the Web-based exercise, The BAGE Page (Figure 1). The goal of this adaptation was to achieve a more efficient and practical use of the experimental procedure in the classroom.

On the home page of this Web site, students were first asked to take a seven-question, pre-exercise quiz. After submitting the quiz electronically, students were then presented with a short, illustrated introduction to electrophoresis that served as their knowledge base for the exercise. In The BAGE Page, we attempted to mirror all steps of the actual laboratory optimization process. Students first selected a beverage. Then, through a series of six steps of optimization, they progressed from performing a failed electrophoresis (no DNA bands visualized) to an excellent electrophoresis (sharp, intense DNA bands visualized). After deciding how to perform each experiment, students received an immediate result with an explanation of why it worked or did not work as expected. In this manner, they encountered successive problems and had to resolve them by performing additional electrophoretic experiments to optimize the results. Each electrophoresis provided new information that could be used in future experimental decisions. Once optimization was completed, the students were asked to complete a survey (Table 1) and a postexercise quiz (Table 2; see Supplemental Material).

\section{Survey Results and Quiz Scores}

The survey (Table 1) was used to assess students' impressions of the exercise, and the results of the pre- and postexercise quiz were used to evaluate pedagogical value (Table 2; see Supplemental Material). In total, 58 high school and undergraduate students performed the exercise. The majority of students responded very positively on the survey regarding their experience with the exercise (Table 1). In response to questions asking whether the exercise was enjoyable and active, and made them think and ask questions, most of the combined groups of high school and undergraduate students agreed (range 62-87\%). By a chi-square test, high school and undergraduate students did not differ in their impressions of the exercise $(p>.05)$, but high school students used more time than undergraduate students to complete the exercise: $15-30 \mathrm{~min}$ for $60 \%$ of high school students compared with $<15 \mathrm{~min}$ for $68 \%$ of undergraduate students $(p<.001)$.

Eighty-seven percent of all students responded that they had a positive learning experience, and an improvement in their quiz scores supports that impression. A single-tailed paired $t$ test was used to test whether the percentage of students answering each question correctly was improved in the postexercise quiz. For most of the seven quiz questions 
$(4-7)$, there was a significant increase in the percentage of correct answers after the exercise $(p=.0095)$. The fraction of correct answers to questions 1-3 correctly did not change ( $p=.293$; Table 2), likely because of the relative ease of the earlier questions (correct answers ranging from 92 to $100 \%$ ) compared with the later questions (correct answers ranging from 22 to $95 \%$ ).

\section{DISCUSSION}

We believe this to be the first demonstration of DNA electrophoresis successfully performed within an unbiased, pseudorandom collection of ions, namely, the common beverages root beer and beer. Our objectives in designing this exercise were fourfold: 1) to introduce DNA gel electrophoresis in a fun, inquiry-based manner to high school and undergraduate students; 2) to encourage students to think critically, beyond the protocol; 3) to show students how an experiment may be optimized from an uncertain starting point; and 4) to convey practically the necessary knowledge base required to perform and discuss DNA electrophoresis.

The first objective was twofold. That the students found our introduction to gel electrophoresis fun and enjoyable was evidenced by the $58 \%$ of high school students and the $68 \%$ of undergraduate students who described the exercise as fun. However, the success of the exercise as a promoting inquiry, per se, was more difficult to assess. To the extent that 67,75 , and $85 \%$ of students agreed that the exercise made them ask questions, was an active process, and made them think, respectively, we can say that we approximated this objective.

The second and third objectives were related. Encouraging students to think critically and beyond the given protocol was built into the design of the exercise insofar as there was no protocol; rather, each student was able to work toward the development of an optimized protocol independently of a procedural guide. After each electrophoresis run, there was an opportunity to critically evaluate the results and redesign the experiment to better optimize the technique.

The last objective was the most straightforward in assessing its success. Eighty percent of undergraduate and 95\% of high school students reported that they learned about electrophoresis, and this sentiment was substantiated: Although we have no objective data for the high school students, the analysis of pre- and postexercise quiz results from the undergraduate students revealed a significant increase in quiz scores after the exercise compared with before the exercise.

A limitation of this analysis is that neither the survey nor the quiz was exhaustive in assessing what the students learned. However, the quiz incorporated a range of difficulty, as evidenced by the greater proportion of students answering the easier questions correctly compared with more difficult questions (Table 2), and the impressions of the students that they learned something being consistent with the improvement in quiz results after the exercise. More prethan postexercise quiz results were received. Because the process is anonymous, there is no way to know why this occurred, or which of the pre-exercise results were unpaired to a postexercise result. Therefore, we included all 45 of the pre-exercise results, and we analyzed the quiz results by question, pairing the pre-exercise to postexercise answers (percent correct).
Disadvantages of this exercise included the exclusion of actual hands-on experience in the laboratory. However, the optimized protocol is available at the completion of the exercise and may be used to see the virtual results replicated in actual form in the laboratory. Another potential disadvantage is the elimination of student-teacher discussions. However, a convenient arrangement that would prevent this potential disadvantage is the incorporation of the 15-min Web-based exercise into a formal, scheduled classroom or laboratory meeting.

The greatest advantage of this interactive exercise is that the value of several days or weeks of experimentation in the laboratory is compacted into approximately $15 \mathrm{~min}$ at a computer. Including preparation and running time, a typical electrophoresis run may require several hours; on the interactive Web site, it requires critical thinking and the click of a mouse. Repeating the experiment with slightly different conditions to optimize results is accomplished in a few more clicks of the mouse. It may be advisable to expand considerably the choices of experimental methods that are taught by inquiry-based virtual laboratories.

The BAGE Page was tested in both high school and undergraduate classes. In both cases, the course was a lecture (classroom-based) forum. The high school students were juniors and seniors in Advanced Placement Biology, and the undergraduates were predominantly first-year students who entered college with credit for Advanced Placement Biology.

\section{CONCLUSIONS}

The BAGE Page provides opportunities to teach students both an understanding of the electrophoretic principles and the problem-solving skills that are required throughout a lifetime of laboratory experience. Its unique advantage is the condensation of several days or weeks of wet-laboratory experimentation into a 15 -min exercise that students can accomplish in one sitting, in or out of the classroom.

\section{REFERENCES}

Aaij, C., and Borst, P. (1972). The gel electrophoresis of DNA. Biochim. Biophys. Acta 269, 192-200.

Bransford, J. D., Brown, A. L., and Cocking, R. R. (2000). How People Learn: Brain, Mind, Experience and School. Washington, DC: The National Academies Press. http://books.nap.edu/books / 0309070368/html/index.html (accessed 20 March 2005).

Brody, J. R., and Kern, S. E. (2004). History and principles of conductive media for standard DNA electrophoresis. Anal. Biochem. $333,1-13$.

Budnitz, N. (2001). Center for Inquiry-Based-Learning. Durham, NC: Duke University. http://www.biology.duke.edu/cibl (accessed 20 March 2005).

Chiappetta, E. L. (1997). Inquiry-based science. Strategies and techniques for encouraging inquiry in the classroom. Sci. Teach. 64, 22-26.

Committee on Undergraduate Biology Education to Prepare Research Scientists for the 21st Century, Board on Life Sciences, Division on Earth and Life Studies, National Research Council of the National Academies (2003). BIO 2010, Transforming Undergraduate Education for Future Research Biologists, Washington, DC: The 
National Academies Press. http://www.nap.edu/books/ 0309085357/html (accessed 20 March 2005).

Gordon, A., Keil, B., Sehesta, K., Knessel, F. (1951). An electrophoretic investigation of the mixture of oligonucleotides formed by the enzymatic degradation of deoxyribonucleic acid by deoxyribonuclease. J. Biochem. 48, 569-575.

Hayward, G. S., and Smith, M. G. (1972). The chromosome of bacteriophage T5. I. Analysis of the single-stranded DNA fragments by agarose gel electrophoresis. J. Mol. Biol. 63, 383-395.

Howard, D. R., and Miskowski, J. A. (2005). Using a module-based laboratory to incorporate inquiry into a large cell biology course. Cell Biol. Educ. 4, 249-260.
Kenny, S. S. (1998). Boyer Commission on Educating Undergraduates in the Research University: Reinventing Undergraduate Education: A Blueprint for America's Research Universities. http:// naples.cc.sunysb.edu/Pres/boyer.nsf (accessed 20 March 2005).

Klamf, C. W. (1999). Analysis of organic and inorganic anions in different types of beer using capillary zone electrophoresis. J. Agric. Food Chem. 47, 987-990.

Leonard, W. H. (2000). How do college students best learn science? J. Coll. Sci. Teach. 29, 385-388.

Rehorek, S. J. (2004). Inquiry-based teaching: an example of descriptive science in action. Am. Biol. Teach. 66, 493-499. 